\title{
To clot, or not to clot - Antithrombotic therapy is the question
}

\author{
E Osuch, ${ }^{1}$ A Marais ${ }^{2}$ \\ 'Department of Pharmacology and Therapeutics, School of Medicine, Sefako Makghato Health Sciences University, South Africa \\ ${ }^{2}$ Department of Pharmacology, School of Medicine, Faculty of Health Sciences, University of Pretoria, South Africa \\ Corresponding author:dramarais@gmail.com / andre.marais@up.ac.za
}

\begin{abstract}
Haemostasis and thrombosis rely on three components namely the vascular endothelial wall, blood platelets and the coagulation cascade. Non-physiologic excessive thrombosis occurs when haemostatic processes are dysfunctional, causing undue clot formation or reduced clot lysis. Antithrombotic agents including antiplatelet, anticoagulation and fibrinolytic agents are essential for the prophylaxis and pharmacological management of venous thromboembolism and arterial thrombosis. Anticoagulation treatment options have expanded steadily over the past few decades, providing a greater number of agents. Anticoagulants that directly target the enzymatic activity of thrombin and factor Xa have recently been developed to address the inadequacies of traditional vitamin $\mathrm{K}$ antagonists. Appropriate use of these agents requires knowledge of their individual characteristics, risks, and benefits.
\end{abstract}

Keywords: anticoagulant, antiplatelet, direct oral anticoagulants (DOACs), haemostasis, thromboembolism, thrombolytic therapy, vitamin K antagonists

\section{Introduction}

Haemostasis, the process of thrombin-stimulated fibrin clot formation at the site of vessel injury, involves several processes. The clotting process involves endothelial injury and formation of the platelet plug, propagation of the clotting process by the coagulation cascade, termination of clotting by antithrombotic regulatory processes, and clot removal by fibrinolysis. ${ }^{1}$ Injury to the endothelium leads to exposure of the circulating blood to subendothelial elements, and activation of platelets and procoagulant factors. The main physiologic platelet stimuli include adenosine diphosphate (ADP), thrombin and collagen. ${ }^{2}$ Intimal injury impairs the production of nitric oxide and prostacyclin and exposes subendothelial collagen. This results in platelet adherence, platelet activation, and secretion of platelets granules. The integrin glycoproteins GPla/lla and GPVI are the two most important platelet collagen receptors, playing critical roles in platelet adhesion and activation. Thrombin activates platelets via G-protein coupled protease-activated receptors (PARs) while ADP binds to two G-protein coupled receptors. ${ }^{3}$ Following activation, platelets undergo significant conformational changes via the GPIIb/IIla receptor on the platelet surface that make the platelets extremely adhesive and leads to binding of both von Willebrand factor (VWF) and fibrinogen. Secretion of platelet granules like ADP, serotonin, and thromboxane A2 $\left(\mathrm{TXA}_{2}\right)$ stimulate and recruit additional platelets, induce vasoconstriction and have potent mitogenic effects on smooth muscle cells. ${ }^{4}$ The interactions between activated platelets and the clotting cascade, exposure of tissue factor at the wound site, and its interaction with factor VIla generate activated factor $X$ which converts prothrombin to thrombin. Thrombin converts fibrinogen from a soluble plasma protein into an insoluble fibrin clot, activates other pro-coagulant factors including factors $\mathrm{V}$,
VIII, XI, XIII, and activates platelets. Thrombin is active in both circulating and clot-bound forms. ${ }^{5}$ Components of the intrinsic pathway (i.e., factors VIII, IX, XI) are responsible for amplification of this process. ${ }^{6}$ In order to restore vessel patency following haemostasis, the clot must be removed by the proteolytic enzyme, plasmin, which is converted from plasminogen, in the presence of tissue plasminogen activator (tPA). Plasmin activity is regulated by vascular endothelial cells that secrete both protease plasminogen activators, and plasminogen activator inhibitors.?

\section{Antiplatelet drugs}

Antiplatelet agents prevent clot formation and growth, and prevent platelet clumping. Antiplatelet drugs are classified according to their site of action. These include drugs that inhibit platelet adhesion, activation, aggregation, and platelet mediated links with inflammation. Platelet activation can be impeded by suppressing the TXA 2 pathway, ADP pathway, thrombin and phosphodiesterase (PDE). ${ }^{8}$

Table 1. Summary of available antiplatelet drugs and mechanism of action

\begin{tabular}{|c|c|}
\hline \multicolumn{2}{|c|}{ Antiplatelet agents } \\
\hline $\begin{array}{l}\text { Thromboxane A2 pathway } \\
\text { inhibitors }\end{array}$ & $\begin{array}{l}\text { - aspirin (Ecotrin', Bayer-Aspirin', } \\
\text { Myoprin }{ }^{\circ} \text { ) }\end{array}$ \\
\hline ADP receptor antagonists & $\begin{array}{l}\text { - } \text { clopidogrel (Clopiwin } 75^{\circ}, \text { Plavix }{ }^{\circ} \text { ) } \\
\text { - ticlopidine (Not available in SA) } \\
\text { - } \text { ticagrelor (Brilinta }) \\
\text { - } \text { cangrelor (Not available in SA) } \\
\text { - } \text { prasugrel (Not available in SA) }\end{array}$ \\
\hline Phosphodiesterase inhibitors & - dipyridamole (Persantinº) \\
\hline Glycoprotein IIb/Illa inhibitors & $\begin{array}{l}\text { - } \text { abciximab (Not available in SA) } \\
\text { - epitifibatide (Not available in SA) } \\
\text { - } \text { tirofiban (Aggrastet }{ }^{\circ} \text { ) }\end{array}$ \\
\hline
\end{tabular}




\section{Thromboxane A2 (TXA2) pathway inhibitors - Aspirin}

Aspirin as an antiplatelet agent (in addition to its antiinflammatory, analgesic and antipyretic effect) at a recommended dose of 75-100 mg daily, is used for the primary and secondary prevention of ischaemic heart disease, stroke and transient ischaemic attack, including the prevention of thrombus formation after cardiac surgery. Aspirin is important in the management of coronary artery disease and acute coronary syndromes. Patients with unstable angina have a $50 \%$ risk reduction in the incidence of fatal and non-fatal myocardial infarction if they are on aspirin treatment. ${ }^{9}$ Low dose aspirin irreversibly acetylates and inhibits COX-1 (only weakly inhibits COX-2) and the formation of TXA2, thus reducing platelet aggregation. Irreversible binding of aspirin to the COX-1 enzyme ensures the inability of new TXA2 to be synthetized, resulting in a permanent effect lasting throughout the lifespan of the platelet (7-10 days)..$^{10}$ Gastrointestinal tract irritation, bleeding, hypersensitivity reactions, such as bronchospasm, rhinitis, urticaria, angioedema, and drug interactions are the major side effects associated with aspirin use. Tinnitus, impaired renal function and hepatotoxicity are more likely to be experienced in higher dosages. Elderly patients are more prone to these side effects even in lower dosages. Due to aspirin's mechanism of action and effect on the clotting system, it is contraindicated in patients with peptic ulceration, haemophilia, thrombocytopenia and other bleeding tendencies, including severe renal and hepatic insufficiency. Aspirin use should be avoided in children and adolescents due to the possibility of life threatening Reye's syndrome. It is a highly plasma protein bound agent, and therefore has the potential to displace other drugs (i.e. antidiabetic agents, methotrexate, warfarin) from their binding sites and thus increasing the risk of toxicity. Concomitant use of other thrombolytic agents increases the risk of haemorrhage and gastrointestinal bleeding, and should generally be avoided. ${ }^{11}$

ADP receptor antagonists- Clopidogrel, Ticlopidine, Ticagrelor, Cangrelor, Prasugrel

ADP receptor antagonists irreversibly inhibit $A D P\left(P_{2} Y_{1}\right.$ and $\left.P_{2} Y_{12}\right)$ receptors on platelets. These agents are employed to reduce the risk of fatal myocardial infarction in acute coronary syndrome, with or without ST segment elevation, and for secondary prevention of thromboembolic diseases, stroke and transient ischaemic attack, or in patients with aspirin intolerance. ${ }^{12}$ Contraindications include active bleeding, intracranial haemorrhage, and severe liver impairment. Drug interactions with aspirin, heparin, warfarin and NSAIDs increase the risk of gastrointestinal bleeding in particular. Common adverse effects include bleeding, gastrointestinal side effects (bleeding, dyspepsia, abdominal pain and diarrhoea), and CNS effects with dizziness, paraesthesia and headache. ${ }^{13}$

Clopidogrel is activated in the liver and is six times more effective than aspirin in preventing platelet aggregation. It has superior tolerability and fewer incidences of bleeding compared to aspirin and ticlopidine. There is competitive CYP2C19 inhibition by omeprazole and esomeprazole, therefore pantoprazole should be considered in patients requiring a PPI whilst taking clopidogrel. ${ }^{14}$ In patients with atrial fibrillation and in those intolerant to warfarin, clopidogrel should be added to aspirin. ${ }^{12}$ Ticlodipine displays fewer gastrointestinal effects compared to aspirin. However, reversible neutropenia and thrombotic thrombocytopenic purpura may be experienced in $<1 \%$ of patients, necessitating therapeutic drug monitoring and regular blood counts. ${ }^{15}$ This drug is no longer available in South Africa.

Ticagrelor and cangrelor are selective and reversible inhibitors of the platelet $P_{2} Y_{12}$ ADP receptor. Cangrelor is not available in South Africa, but these agents are used in combination with aspirin or clopidogrel to prevent thromboembolic events in patients with acute coronary syndrome. Contraindications for ticagrelor's use include hypersensitivity, active bleeding, inherited bleeding disorders, intracranial haemorrhage, severe liver impairment, and the concomitant use CYP3A4 inhibitors/ inducers. It increases plasma levels of statins and digoxin. ${ }^{16}$

Prasugrel is used with aspirin to reduce atherothrombotic events after stenting. It can be co-administered with CYP3A4 inhibitors/inducers, statins and PPIs. Prasugrel causes irreversible inhibition of the platelet $\mathrm{P} 2 \mathrm{Y}_{12}$ ADP receptor, which results in a fast, powerful and sustained inhibition of platelet aggregation compared to clopidogrel. ${ }^{17}$

\section{Phosphodiesterase inhibitors - Dipyridamole}

Dipyridamole blocks the platelet aggregation response by inhibiting phosphodiesterase activity which is responsible to break down cAMP. In addition, the ability of platelets to establish the re-uptake of adenosine is impaired, thereby resulting in increased plasma concentrations of adenosine. Dipyridamole is used in combination with other antiplatelet drugs for reducing thromboembolic complications associated with prosthetic heart valves, and is used as add-on therapy to warfarin in the secondary prevention of ischaemic stroke and TIA. ${ }^{18}$

\section{Glycoprotein Ilb/IIla inhibitors - Abciximab, Eptifibatide, Tirofiban}

Glycoprotein Ilb/Illa platelet receptor antagonists block the final pathway in platelet aggregation and clot formation. Tirofiban is the only glycoprotein inhibitor currently available in South Africa. These drugs are expensive and reserved for high-risk patients undergoing percutaneous coronary interventions, as adjunctive to heparin and aspirin for the prevention of ischaemic complications, short term myocardial infarction risk reduction in patients with unstable angina, and non-STEMI not responding to conventional therapy. ${ }^{19}$ Renal impairment necessitates dose adjustment, and major side effects include bleeding and thrombocytopenia. Overdose is managed by treatment discontinuation, administering desmopressin, platelets and recombinant factor VIla. ${ }^{20}$ 


\section{Fibrinolytic drugs}

\section{Alteplase (recombinant tissue type plasminogen activator, tPA), streptokinase, tenecteplase, urokinase, lanoteplase and reteplase}

Thrombolytic drugs convert plasminogen to plasmin in order to degrade fibrin and fibrinogen. Therapeutic indications comprise the management of acute thrombotic disorders including acute myocardial infarction (STEMI), ischaemic stroke (if administered within 4 hours from angiographically proven vascular occlusion), acute pulmonary embolism, acute arterial thrombosis and deep vein thrombosis. However, thrombolytic treatment is not recommended for unstable angina and non- $Q$ wave infarction, non-ST elevation MI (NSTEMI) or superficial thrombophlebitis. ${ }^{21}$ Bleeding is the primary complication of thrombolytic therapy and haemorrhagic stroke is the greatest concern. Absolute contraindications to fibrinolytic therapy include previous intracranial haemorrhage, structural cerebral vascular lesions, malignant intracranial neoplasms, ischemic stroke within three months, suspected aortic dissection, active bleeding or bleeding diathesis, or significant head or facial trauma within three months. ${ }^{22}$ Relative contraindications include poorly controlled hypertension (systolic blood pressure $>180 \mathrm{mmHg}$ ), ischemic stroke more than three months previously, dementia or other intracranial pathology, traumatic or prolonged cardiopulmonary resuscitation (> 10 minutes) or major surgery (within $<3$ weeks), recent (within two to four weeks) internal bleeding, noncompressible vascular puncture, pregnancy, active peptic ulcer, and current use of anticoagulants. Intraocular haemorrhage from fibrinolytic therapy in patients with diabetes mellitus is rare and diabetic retinopathy should not be considered a contraindication to fibrinolytic therapy in acute myocardial infarction. ${ }^{23}$

Currently available fibrinolytic drugs registered in South Africa include streptokinase (Streptase'), alteplase (Actilyse ${ }^{\circ}$ ) and tenecteplase (Metalyse ${ }^{\circ}$ ). Streptokinase, a polypeptide derived from beta-haemolytic streptococcus cultures, is the most widely used fibrinolytic agent worldwide due to the relatively low cost and reasonable efficacy to safety ratio. ${ }^{24}$ It binds to plasminogen, forming an active enzyme that activates plasmin. Streptokinase is less efficacious than alteplase, but displays a lower risk of intracranial haemorrhage. The most common adverse effects include bleeding, allergic reactions and hypotension. Antistreptokinase antibodies remain elevated for up to 7 years after treatment, suggesting that an allergic reaction may occur with re-treatment many years after the first exposure. ${ }^{25}$

Alteplase (tPA) is a non-antigenic naturally occurring enzyme produced by a number of tissues including endothelial cells. In contrast to streptokinase, it is fibrin-specific, thereby having an increased affinity for plasminogen and enhanced clot lysis. It has a short distribution half-life (about four minutes) and elimination half-life about 35 minutes. Differing from streptokinase, alteplase results in less fibrinogen depletion and is not associated with allergic or hypotensive effects. ${ }^{26}$ Oro-lingual angioedema is typically mild and transient. Severe oro-lingual angioedema is rare but may cause partial airway obstruction and require emergency airway management. ${ }^{27}$
Tenecteplase (TNK-tPA) is a genetically engineered, recombinant tissue-type plasminogen activator (tPA) that has a longer plasma half-life allowing for a single intravenous bolus injection. It is approximately 14 times more fibrin specific and has an 80-fold higher resistance to inhibition by plasminogen activator inhibitor 1(PAI-1) than tPA. Tenecteplase bolus administration is less complicated and faster to conduct compared to streptokinase and alteplase. ${ }^{28}$

Urokinase, lanoteplase and reteplase are fibrinolytic agents which are not currently available in South Africa. Reteplase (recombinant plasminogen activator, rPA) is a non-glycosylated deletion mutant of wild-type recombinant tissue-type plasminogen activator (tPA). Reteplase is less fibrin selective and has a longer half-life than alteplase. ${ }^{29}$ Urokinase is a nonselective plasminogen activator that has no specific affinity for fibrin, thereby activating fibrin-bound and circulating plasminogen indiscriminately. It is the major activator of fibrinolysis in the extravascular compartment in contrast to tPA which is largely responsible for initiating intravascular fibrinolysis. It is currently used only in the management of pulmonary embolism. ${ }^{30}$

\section{Anticoagulant drugs}

Anticoagulants include a variety of agents that inhibit one or more steps in the coagulation cascade, thereby slowing down clotting, reducing the formation of fibrin or preventing clots from forming. Their mechanisms vary, including direct enzymatic inhibition, indirect inhibition by binding to antithrombin III, and antagonism of vitamin K-dependent factors by altering their hepatic synthesis and calcium-binding properties. Available agents include unfractionated heparin, low molecular weight heparins, fondaparinux, vitamin $\mathrm{K}$ antagonists, direct thrombin inhibitors, direct factor $X a$ inhibitors, and other agents at various stages of development. ${ }^{31}$

Table 2. Summary of available anticoagulant drugs

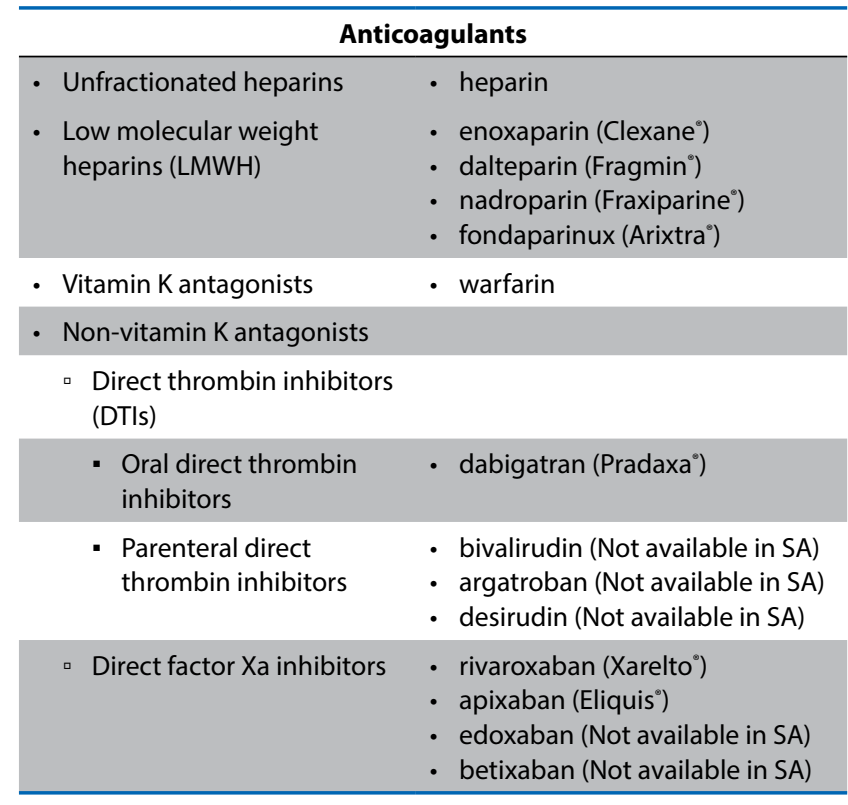




\section{Unfractionated heparins}

Heparin enhances the activity of antithrombin III that in return inhibits the action of factors XII, XI, IX, X and II. Heparin treatment in unstable angina reduces the risk of progression to myocardial infarction and associated mortality by approximately $80 \%$. It is used in the treatment and prophylaxis (especially after abdominal, orthopaedic and gynaecological surgery, or in patients with malignancy) of deep vein thrombosis (DVT), pulmonary embolism (PE), unstable angina, and acute non ST elevated myocardial infarction (non-STEMI) when rapid anticoagulation is required. Monitoring of partial thromboplastin time is essential. ${ }^{32}$ Contraindications for heparin use include hypersensitivity and paradoxical heparin-induced thrombocytopenia associated with thromboembolism. Skin necrosis may occur at the injection site and prolonged use has been associated with osteoporosis. Protamine sulphate is used as a heparin antidote. ${ }^{33}$

\section{Low molecular weight heparins (LMWH) - Enoxaparin, Dalteparin, Nadroparin, Fondaparinux}

LMWH have more anti-Xa activity and longer duration of action compared to unfractionated heparins. These agents display superior anticoagulant predictability, and have a lower incidence of thrombocytopenia. Titrated correctly according to body weight, LMWH provides effective anticoagulation and does not require regular monitoring of the activated partial thromboplastin time. If treatment continues for prolonged periods, regular platelet counts should be performed to monitor for the development of thrombocytopenia. In addition to the same indications as heparin, a combination of LMWH and aspirin should be used instead of unfractionated heparin to treat patients with unstable angina. ${ }^{34}$ Fondaparinux is a synthetic pentasaccharide, chemically related to LMWH but with no effect on thrombin (inhibiting only factor $\mathrm{Xa}$ ) and has a decreased risk of causing bleeding. Although bleeding complications with LMWH are infrequently encountered, there is no antidote available in case of an overdose, and management remains supportive. Fortunately, however, bleeding complications related to LMWH are infrequent. ${ }^{33}$

\section{Vitamin K antagonists -Warfarin}

Warfarin is an oral anticoagulant effective in primary and secondary prevention of venous thromboembolism and arterial embolism in patients with atrial fibrillation or prosthetic heart valves. It acts by inhibiting the hepatic synthesis of vitamin $\mathrm{K}$ dependant coagulation factors II, VII, IX, X, and natural anticoagulant protein $C$ and $S .{ }^{35}$ Drug interactions, very slow onset of action (half-life about 40 hours) and inconsistent response are considerable limitations to its use. It has a narrow therapeutic window and more variable dose-response relationship that depends on a variety of factors. These features necessitate the frequent monitoring of clotting times to optimize the therapeutic dose range and prevent bleeding. ${ }^{36}$ A wide variety of drug interactions involving multiple mechanisms can occur with warfarin use. These include displacement from the albumin binding sites, inhibition or induction of hepatic cytochrome enzymes, and the interference with absorption and metabolism of other drugs known to have antithrombotic effects. Its effect can additionally be altered by changes in the diet, administration of herbal supplements, the presence of certain gastrointestinal disorders, and acute medical illness. The level of vitamin $\mathrm{K}$ intake and production in the gastrointestinal tract, as well as induction of hepatic cytochromes affect warfarin pharmacokinetics. Genetic polymorphisms of the VKORC1 gene which is responsible of regulating the vitamin $\mathrm{K}$ epoxide reductase enzyme, can result in both over- or under coagulation on warfarin treatment, thus dose adjustment may be necessary. ${ }^{37}$ Contraindications for its use include bleeding disorders, recent stroke, active or recent bleeding, infective endocarditis, aneurism, severe hypertension, recent eye, brain or spinal cord surgery and hypersensitivity reactions. The risk of bleeding should be carefully evaluated in patients with chronic liver disease, portal hypertension, renal disease and in geriatric and paediatric patients. The international normalised ratio (INR target between 2.5-3.5) should be determined at baseline, then on alternate days for 2 weeks, then weekly for 1 month, thereafter monthly for 1 year and if stable 3 monthly. Patients experiencing difficulty in controlling INR may benefit from direct oral anticoagulants (DOACs). However, vitamin $\mathrm{K}$ antagonists remain significantly less expensive than DOACs. Warfarin is highly teratogenic and contraindicated in pregnancy. Low molecular weight heparins are the drug of choice in pregnant females requiring antithrombotic therapy. Warfarin overdose is treated with intravenous administration of vitamin $\mathrm{K}$, followed by factor IX, fresh human plasma, or packed cell concentrate (PCC). Providing recombinant factor VIla is reserved for patients with life-threatening bleeding complications not responding to conventional therapy. ${ }^{33}$

\section{Direct oral anticoagulants (DOACs) / novel oral anticoagulants (NOACs) or non-vitamin Kantagonists}

The direct oral anticoagulants (DOACs) represent the newer class of non-vitamin $\mathrm{K}$ antagonists, only approved as recently as 2010. They differ significantly from vitamin $\mathrm{K}$ antagonists in their onset of action, half-life, drug-drug interactions, and availability of antidotes when excessive bleeding may occur. DOACs are administered in the absence of monitoring of drug levels or clotting times. These agents are contraindicated in patients with prosthetic heart valves (due to increased risk of fatal valve thrombosis), pregnancy and severe hepatic impairment. Dose reduction of direct factor $\mathrm{Xa}$ inhibitors in patients with renal impairment is recommended.

\section{Direct thrombin inhibitors (DT/s)}

Direct thrombin inhibitors (DTIs) prevent thrombin from cleaving fibrinogen to fibrin. They bind to both soluble thrombin and fibrin-bound thrombin. Unlike heparin, the direct thrombin inhibitors do not require a co-factor such as antithrombin to elicit their effect. In addition, DTIs bind to platelet factor 4 (PF4), and are therefore not able to induce or react with the anti-heparin/PF4 antibodies responsible for causing heparin-induced thrombocytopenia (HIT). Parenteral DTls are effective anticoagulants for patients with HIT. The oral direct 
thrombin inhibitors, or oral direct factor Xa inhibitors, are usually administered at fixed doses without laboratory monitoring. ${ }^{39}$

\section{Oral direct thrombin inhibitors - dabigatran}

Dabigatran is a prodrug that requires conversion to the active form by the liver. The maximum anticoagulant effect is achieved within 2-3 hours after ingestion. Dabigatran has a half-life of approximately 15 hours, and its absorption is unaffected by food. It is metabolised by the kidney (and not by the cytochrome p450 system), resulting in an extended half-life in elderly patients, or those with renal insufficiency. Dose reduction should be considered in these patients. It is a substrate for P-glycoprotein, therefore concomitant use with P-glycoprotein inducers (e.g., rifampicin) reduces the anticoagulant effect, whereas simultaneous use with P-glycoprotein inhibitors (e.g., ketoconazole, verapamil) may increase the anticoagulant effect. ${ }^{40}$ Avoidance of dabigatran in individuals with a body mass index $(\mathrm{BMI})>40 \mathrm{~kg} / \mathrm{m}^{2}$, or weight $\geq 120 \mathrm{~kg}$ is recommended due to an increased risk of various emboli observed with the fixed dose formulation. ${ }^{41}$ Dabigatran is associated with a lower risk of osteoporotic fractures than warfarin..$^{42}$ It is indicated in the treatment and prophylaxis of venous thromboembolic disease, stroke circumvention in patients with atrial fibrillation (AF). It should be avoided during pregnancy, or patients with prosthetic heart valves. Laboratory testing prior to initiating dabigatran should include platelet count, prothrombin time (PT), activated partial thromboplastin time (aPTT), and serum creatinine measurement. Routine laboratory monitoring of coagulation times is not required..$^{43}$ Premature discontinuation of dabigatran has been associated with an increased risk of intracranial haemorrhage, gastrointestinal bleeding and nonbleeding gastrointestinal events (dyspepsia, gastrointestinal reflux) and other thrombotic events. ${ }^{44}$ Idarucizumab (not registered in South Africa) is the only anticoagulant reversal agent for dabigatran..$^{45}$

\section{Parenteral direct thrombin inhibitors - bivalirudin, argatroban, desirudin}

None of these agents is currently available in South Africa. They have limited use and are currently only indicated for heparininduced thrombocytopenia and percutaneous coronary interventions. Bivalirudin is a synthetic amino acid peptide that binds to the thrombin catalytic site reversibly inhibiting thrombin enzymatic activity. Intravenous administration produces an immediate anticoagulant effect. The drug is primarily metabolised by the liver and the kidney. However, patients with renal failure do not require dosage adjustment. The halflife of bivalirudin is approximately 25 minutes and prolonged coagulation times return to normal approximately one hour after discontinuation. Bivalirudin can be haemodialysed and be monitored by the activated clotting time (ACT) and the activated partial thromboplastin time (aPTT), with a target of 1.5 to 2.5 times the normal range. ${ }^{46}$ Argatroban is also a synthetic peptide that interrelates with the active site of thrombin. It has a short in vivo plasma half-life (terminal elimination half-life approximately 40 to 50 minutes), and is exclusively metabolised by the liver. Argatroban is safe for use in patients with renal dysfunction and no dosage adjustment is required compared to bivalirudin. ${ }^{47}$ Desiudin is a recombinant hirudin derivative that inhibits free and clot-bound thrombin. The half-life is approximately two hours and may be increased in patients with renal insufficiency. ${ }^{48}$

\section{Direct factor Xa inhibitors - rivaroxaban, apixaban, edoxaban, betixaban}

Rivaroxaban and apixaban are the only direct factor Xa inhibitors available in South Africa. These agents block the action of both the circulating and clot-bound forms of factor Xa. This mechanism is unlike the indirect factor Xa inhibitors (heparin and fondaparinux) which are only able to inactivate circulating factor Xa via antithrombin. ${ }^{49}$ Clinical indications for direct factor Xa inhibitors include venous thromboembolism (VTE) prophylaxis in hip and knee replacement surgery (Apixaban \& Rivaroxaban), VTE treatment - individuals with or without cancer (only Rivaroxaban), stroke prevention in non-valvular atrial fibrillation (NVAF) (Apixaban and Rivaroxaban), acute coronary syndromes (none registered in South Africa), and heparin induced thrombocytopenia. These drugs have half-lives between 5 and 9 hours, and display drug interactions with dual inhibitors of CYP3A4 and P-glycoprotein such as ketoconazole..$^{50}$

Laboratory testing prior to administration of these agents should include prothrombin time (PT) and activated partial thromboplastin time (aPTT), serum creatinine, as a baseline and for potential dose adjustment in renal insufficiency. Direct factor Xa inhibitors are not recommended in patients with a creatinine clearance $<30 \mathrm{~mL} /$ minute since impaired glomerular filtration will inhibit renal elimination, resulting in an increase in drug exposure. Similarly, drug accumulation could be present in patients with severe hepatic impairment and dose adjustments should be considered in liver diseases. These agents should be avoided during pregnancy and in patients with a body mass index $(\mathrm{BMI})>40 \mathrm{~kg} / \mathrm{m}^{2}$. Routine monitoring of coagulation times is not required. ${ }^{51} \mathrm{~A}$ recombinant modified factor Xa protein (andexanet alfa), has recently been approved by the FDA as a reversal agent for rivaroxaban and apixaban in patients with life-threatening, or uncontrolled bleeding. ${ }^{52}$ This agent is not yet available in South Africa.

\section{Conclusion}

Although antithrombotic drugs are widely used for the prevention and treatment of arterial and venous thrombosis, thromboembolic diseases are still a major cause of death and disability worldwide. Anticoagulants and antiplatelet drugs are key therapeutic agents in the treatment of cardiovascular diseases. Given different mechanisms of action, combining these agents holds the potential for additive and perhaps even synergistic reductions in thromboembolic morbidity and mortality. Family physicians and health care professionals have an important role to play in the prevention, treatment and risk reduction of thrombosis, including provision of accurate, up-todate information to their patients. In addition to pharmacological management, every effort should be made to encourage patients to make healthy lifestyle choices with regards to factors such as smoking, obesity, exercise and their diet. 


\section{References}

1. Furie B, Furie BC. Mechanisms of thrombus formation. N Engl J Med. 2008;359(9):938-49. PMCID:18753650. DOI:10.1056/NEJMra0801082.

2. Shen J, Sampietro S, Wu J, Tang J, Gupta S, Matzko CN, et al. Coordination of platelet agonist signaling during the hemostatic response in vivo. Blood Adv. 2017;1(27):2767-75. PMCID:PMC5745130. DOI:10.1182/ bloodadvances.2017009498.

3. Hollopeter G, Jantzen HM, Vincent D, Li G, England L, Ramakrishnan V, et al. Identification of the platelet ADP receptor targeted by antithrombotic drugs. Nature. 2001;409(6817):202-7. DOI:10.1038/35051599.

4. Pan J, Dinh TT, Rajaraman A, Lee M, Scholz A, Czupalla CJ, et al. Patterns of expression of factor VIII and von Willebrand factor by endothelial cell subsets in vivo. Blood. 2016;128(1):104-9. PMCID:PMC4937354. DOI:10.1182/ blood-2015-12-684688.

5. Krishnaswamy $\mathrm{S}$. The transition of prothrombin to thrombin. J Thromb Heamost. 2013;11:265-76. DOI:doi.org/10.1111/jth.12217

6. Weidmann $\mathrm{H}$, Heikaus L, Long AT, Naudin $\mathrm{C}$, Schluter $\mathrm{H}$, Renne T. The plasma contact system, a protease cascade at the nexus of inflammation, coagulation and immunity. Biochim Biophys Acta Mol Cell Res. 2017;1864(11 Pt B):2118-27. DOI:10.1016/j.bbamcr.2017.07.009.

7. Von dem Borne PA, Bajzar L, Meijers JC, Nesheim ME, Bouma BN. Thrombinmediated activation of factor XI results in a thrombin-activatable fibrinolysis inhibitor-dependent inhibition of fibrinolysis. J Clin Invest. 1997;99(10):2323-7. PMCID:PMC508069. DOI:10.1172/jci119412.

8. Ruggeri ZM. Platelets in atherothrombosis. Nat Med. 2002;8(11):1227-34. PMCID:12411949. DOI:10.1038/nm1102-1227.

9. Rothwell PM, Algra A, Chen Z, Diener HC, Norrving B, Mehta Z. Effects of aspirin on risk and severity of early recurrent stroke after transient ischaemic attack and ischaemic stroke: time-course analysis of randomised trials. Lancet. 2016;388(10042):365-75. PMCID:PMC5321490. DOI:10.1016/ s0140-6736(16)30468-8.

10. Clarke RJ, Mayo G, Price P, FitzGerald GA. Suppression of thromboxane A2 but not of systemic prostacyclin by controlled-release aspirin. N Engl J Med. 1991;325(16):1137-41. DOI:10.1056/nejm199110173251605.

11. Li L, Geraghty OC, Mehta Z, Rothwell PM. Age-specific risks, severity, time course, and outcome of bleeding on long-term antiplatelet treatment after vascular events: a population-based cohort study. Lancet. 2017;390(10093):490-9. PMCID:PMC5537194. DOI:10.1016/s0140-6736(17)30770-5.

12. Johnston SC, Easton JD, Farrant M, Barsan W, Conwit RA, Elm JJ, et al. Clopidogrel and Aspirin in Acute Ischemic Stroke and High-Risk TIA. N Engl J Med. 2018;379(3):215-25. PMCID:PMC6193486. DOI:10.1056/NEJMoa1800410.

13. Bellemain-Appaix A, O' Connor SA, Silvain J, Cucherat M, Beygui F, Barthelemy $O$, et al. Association of clopidogrel pretreatment with mortality, cardiovascular events, and major bleeding among patients undergoing percutaneous coronary intervention: a systematic review and meta-analysis. Jama. 2012;308(23):250716. DOI:10.1001/jama.2012.50788.

14. Wang $Y$, Zhao X, Lin J, Li H, Johnston SC, Lin Y, et al. Association Between CYP2C19 Loss-of-Function Allele Status and Efficacy of Clopidogrel for Risk Reduction Among Patients With Minor Stroke or Transient Ischemic Attack. Jama. 2016;316(1):70-8. DOI:10.1001/jama.2016.8662.

15. Jacob S, Dunn BL, Qureshi ZP, Bandarenko N, Kwaan HC, Pandey DK, et al. Ticlopidine-, clopidogrel-, and prasugrel-associated thrombotic thrombocytopenic purpura: a 20-year review from the Southern Network on Adverse Reactions (SONAR). Semin Thromb Hemost. 2012;38(8):845-53. PMCID:PMC3804561. DOI:10.1055/s-0032-1328894.

16. Berwanger O, Nicolau JC, Carvalho AC, Jiang L, Goodman SG, Nicholls SJ, et al. Ticagrelor vs Clopidogrel After Fibrinolytic Therapy in Patients With ST-Elevation Myocardial Infarction: A Randomized Clinical Trial. JAMA cardiology. 2018;3(5):391-9. PMCID:PMC5875327. DOI:10.1001/jamacardio.2018.0612.

17. Motovska Z, Hlinomaz O, Miklik R, Hromadka M, Varvarovsky I, Dusek J, et al. Prasugrel Versus Ticagrelor in Patients With Acute Myocardial Infarction Treated With Primary Percutaneous Coronary Intervention: Multicenter Randomized PRAGUE-18 Study. Circulation. 2016;134(21):1603-12. DOI:10.1161/ circulationaha.116.024823.

18. Bath PM, Woodhouse LJ, Appleton JP, Beridze M, Christensen H, Dineen $\mathrm{RA}$, et al. Antiplatelet therapy with aspirin, clopidogrel, and dipyridamole versus clopidogrel alone or aspirin and dipyridamole in patients with acute cerebral ischaemia (TARDIS): a randomised, open-label, phase 3 superiority trial. Lancet. 2018;391(10123):850-9. PMCID:PMC5854459. DOI:10.1016/ s0140-6736(17)32849-0.

19. Boersma $E$, Harrington RA, Moliterno DJ, White $H$, Theroux $P$, Van de Werf $F$, et al. Platelet glycoprotein Ilb/llla inhibitors in acute coronary syndromes: a meta-analysis of all major randomised clinical trials. Lancet. 2002;359(9302):18998. DOI:10.1016/s0140-6736(02)07442-1.

20. Ingerslev J, Vanek T, Culic S. Use of recombinant factor VIla for emergency reversal of anticoagulation. J Postgrad Med. 2007;53(1):17-22. PMCID:17244965.

21. Llevadot J, Giugliano RP, Antman EM. Bolus fibrinolytic therapy in acute myocardial infarction. Jama. 2001;286(4):442-9.

22. Berkowitz SD, Granger CB, Pieper KS, Lee KL, Gore JM, Simoons M, et al. Incidence and predictors of bleeding after contemporary thrombolytic therapy for myocardial infarction. The Global Utilization of Streptokinase and Tissue Plasminogen activator for Occluded coronary arteries (GUSTO) I Investigators. Circulation. 1997;95(11):2508-16.

23. Simoons M, Krzeminska-Pakula M, Alonso A, Goodman S, Kali A, Loos U, et al. Improved reperfusion and clinical outcome with enoxaparin as an adjunct to streptokinase thrombolysis in acute myocardial infarction. The AMI-SK study. Eur Heart J. 2002;23(16):1282-90.

24. ISIS-3: a randomised comparison of streptokinase vs tissue plasminogen activator vs anistreplase and of aspirin plus heparin vs aspirin alone among 41,299 cases of suspected acute myocardial infarction. ISIS-3 (Third International Study of Infarct Survival) Collaborative Group. Lancet. 1992;339(8796):753-70.

25. Squire IB, Lawley W, Fletcher S, Holme E, Hillis WS, Hewitt C, et al. Humoral and cellular immune responses up to 7.5 years after administration of streptokinase for acute myocardial infarction. Eur Heart J. 1999;20(17):1245-52. DOI:10.1053/ euhj.1999.1528.

26. A comparison of continuous infusion of alteplase with double-bolus administration for acute myocardial infarction. N Engl J Med. 1997;337(16):112430. DOI:10.1056/nejm199710163371604.

27. Myslimi F, Caparros F, Dequatre-Ponchelle N, Moulin S, Gautier S, Girardie $\mathrm{P}_{\text {, et }}$ al. Orolingual Angioedema During or After Thrombolysis for Cerebral Ischemia. Stroke. 2016;47(7):1825-30. DOI:10.1161/strokeaha.116.013334.

28. Sinnaeve PR, Alexander JH, Bogaerts K, Belmans A, Wallentin L, Armstrong $P$, et al. Efficacy of tenecteplase in combination with enoxaparin, abciximab, or unfractionated heparin: one-year follow-up results of the Assessment of the Safety of a New Thrombolytic-3 (ASSENT-3) randomized trial in acute myocardial infarction. Am Heart J. 2004;147(6):993-8. DOI:10.1016/j.ahj.2003.12.028.

29. Topol EJ, Ohman EM, Armstrong PW, Wilcox R, Skene AM, Aylward P, et al. Survival outcomes 1 year after reperfusion therapy with either alteplase or reteplase for acute myocardial infarction: results from the Global Utilization of Streptokinase and t-PA for Occluded Coronary Arteries (GUSTO) III Trial. Circulation. 2000;102(15):1761-5.

30. The UKEP study: multicentre clinical trial on two local regimens of urokinase in massive pulmonary embolism. The UKEP Study Research Group. Eur Heart J. 1987:8(1):2-10.

31. Berge E, Sandercock P. Anticoagulants versus antiplatelet agents for acute ischaemic stroke. The Cochrane database of systematic reviews. 2002;10.1002/14651858.cd003242(4):Cd003242. DOI:10.1002/14651858. cd003242.

32. Garcia DA, Baglin TP, Weitz J, Samama MM. Parenteral anticoagulants: Antithrombotic Therapy and Prevention of Thrombosis, 9th ed: American College of Chest Physicians Evidence-Based Clinical Practice Guidelines. Chest. 2012;141(2 Suppl):e24S-e43S. PMCID:PMC3278070. DOI:10.1378/chest.11-2291.

33. Piran S, Schulman S. Treatment of bleeding complications in patients on anticoagulant therapy. Blood. 2019;133(5):425-35. DOI:10.1182/ blood-2018-06-820746.

34. Antman EM, Louwerenburg HW, Baars HF, Wesdorp JC, Hamer B, Bassand JP, et al. Enoxaparin as adjunctive antithrombin therapy for ST-elevation myocardial infarction: results of the ENTIRE-Thrombolysis in Myocardial Infarction (TIMI) 23 Trial. Circulation. 2002;105(14):1642-9.

35. Johnson SG, Witt DM, Eddy TR, Delate T. Warfarin and antiplatelet combination use among commercially insured patients enrolled in an anticoagulation management service. Chest. 2007;131(5):1500-7. DOI:10.1378/chest.06-2374.

36. Kearon C, Kahn SR, Agnelli G, Goldhaber S, Raskob GE, Comerota AJ. Antithrombotic therapy for venous thromboembolic disease: American College of Chest Physicians Evidence-Based Clinical Practice Guidelines (8th Edition). Chest. 2008;133(6 Suppl):454s-545s. PMCID:18574272. DOI:10.1378/ chest.08-0658. 
37. Czogalla KJ, Liphardt K, Honing K, Hornung V, Biswas A, Watzka M, et al. VKORC1 and VKORC1L1 have distinctly different oral anticoagulant dose-response characteristics and binding sites. Blood Adv. 2018;2(6):691-702. PMCID:PMC5873226. DOI:10.1182/bloodadvances.2017006775.

38. Khachatryan T, Hauschild C, Hoff J, Contractor T, Khachatryan A, Tran H, et al. Review of Direct Oral Anticoagulants and Guide for Effective Drug Utilization. Am J Cardiovasc Drugs. 2019;10.1007/s40256-019-00344-6. DOI:10.1007/ s40256-019-00344-6.

39. Di Nisio M, Middeldorp S, Buller HR. Direct thrombin inhibitors. N Engl J Med. 2005;353(10):1028-40. PMCID:16148288. DOI:10.1056/NEJMra044440.

40. Blech S, Ebner T, Ludwig-Schwellinger $E$, Stangier J, Roth W. The metabolism and disposition of the oral direct thrombin inhibitor, dabigatran, in humans. Drug Metab Dispos. 2008;36(2):386-99. PMCID:18006647. DOI:10.1124/ dmd.107.019083.

41. Martin K, Beyer-Westendorf J, Davidson BL, Huisman MV, Sandset PM, Moll S. Use of the direct oral anticoagulants in obese patients: guidance from the SSC of the ISTH. J Thromb Haemost. 2016;14(6):1308-13. PMCID:PMC4936273. DOI:10.1111/ jth. 13323.

42. Lau WC, Chan EW, Cheung CL, Sing CW, Man KK, Lip GY, et al. Association Between Dabigatran vs Warfarin and Risk of Osteoporotic Fractures Among Patients With Nonvalvular Atrial Fibrillation. Jama. 2017;317(11):1151-8. DOI:10.1001/jama.2017.1363.

43. Gosselin RC, Adcock DM, Bates SM, Douxfils J, Favaloro EJ, Gouin-Thibault I, et al. International Council for Standardization in Haematology (ICSH) Recommendations for Laboratory Measurement of Direct Oral Anticoagulants. Thromb Haemost. 2018;118(3):437-50. PMCID:29433148. DOI:10.1055/s-0038-1627480.
44. Southworth MR, Reichman ME, Unger EF. Dabigatran and postmarketing reports of bleeding. N Engl J Med. 2013;368(14):1272-4. PMCID:23484796 DOI:10.1056/ NEJMp1302834.

45. Syed YY. Idarucizumab: A Review as a Reversal Agent for Dabigatran. Am J Cardiovasc Drugs. 2016;16(4):297-304. PMCID:27388764 DOI:10.1007/ s40256-016-0181-4.

46. Warkentin TE, Greinacher A, Koster A. Bivalirudin. Thromb Haemost. 2008;99(5):830-9. PMCID:18449412. DOI:10.1160/th07-10-0644.

47. Swan SK, Hursting MJ. The pharmacokinetics and pharmacodynamics of argatroban: effects of age, gender, and hepatic or renal dysfunction. Pharmacotherapy. 2000;20(3):318-29. PMCID:10730687.

48. Graetz TJ, Tellor BR, Smith JR, Avidan MS. Desirudin: a review of the pharmacology and clinical application for the prevention of deep vein thrombosis. Expert Rev Cardiovasc Ther. 2011;9(9):1101-9. PMCID:21932952. DOI:10.1586/erc.11.131.

49. Samama MM. The mechanism of action of rivaroxaban--an oral, direct Factor Xa inhibitor--compared with other anticoagulants. Thromb Res. 2011;127(6):497504. PMCID:20888031. DOI:10.1016/j.thromres.2010.09.008.

50. Lassen MR, Ageno W, Borris LC, Lieberman JR, Rosencher N, Bandel TJ, et al. Rivaroxaban versus enoxaparin for thromboprophylaxis after total knee arthroplasty. N Engl J Med. 2008;358(26):2776-86. PMCID:18579812. DOI:10.1056/NEJMoa076016.

51. Almarshad F, Alaklabi A, Bakhsh E, Pathan A, Almegren M. Use of direct oral anticoagulants in daily practice. Am J Blood Res. 2018;8(4):57-72. PMCID:PMC6334188.

52. Heo YA. Andexanet Alfa: First Global Approval. Drugs. 2018;78(10):1049-55. PMCID:PMC6061403. DOI:10.1007/s40265-018-0940-4. 